\title{
A VIOLÊNCIA DO CAPITAL OBJETIVADA N'O MECANISMO DA TELEVISÃO
}

\author{
THE VIOLENCE OF CAPITAL OBJECTIFIED \\ IN THE MECHANISM OF THE TELEVISION
}

\section{LA VIOLENCIA DEL CAPITAL SE OBJETIVA EN EL MECANISMO DE LA TELEVISIÓN}

\author{
André Barcellos Carlos de Souza ${ }^{1}$ \\ ${ }^{1}$ Universidade Federal de Goiás (UFG), Goiânia/GO - Brasil
}

\begin{abstract}
Resumo Este texto discute como a violência do capital é objetivada na televisão em geral e na série televisiva da Netflix $O$ Mecanismo, de José Padilha. O autor/diretor, ao estabelecer n'O Mecanismo a corrupção como o "câncer" da sociedade capitalista, deliberadamente elege algo da ordem do subjetivo, da moral, como causa das condições desiguais da sociedade do capital, deslocando intencionalmente ou não as determinações sociais objetivas para o plano subjetivo. Problematiza também as relações contraditórias entre as relações sociais de produção e as forças produtivas na arte e na indústria cultural, fundamentando-se nas contribuições teóricas de Marx, Adorno e Horkheimer. Ademais, postula que a televisão brasileira, imbricada com o capitalismo tardio, é um objeto cujo procedimento de razão atua não apenas na esfera da reprodução da cultura, mas, fundamentalmente, na sua produção pela via da formação do público. Nesse sentido, discute os limites e as possibilidades dos processos formativos e educativos da televisão.
\end{abstract}

Palavras-chave: EducaÇ̃̃o; Indústria cultural; Televisão.

Abstract This article discusses the violence of capital embodied in general television content and in the series "The Mechanism" by José Padilha. The creator/director, establishing in "The Mechanism" political corruption as the "cancer" of capitalist society, deliberately elects something subjective, of moral content, as the cause of inequality in today's capitalist world, intentionally or not, dislocating the objective social aspects that cause such effect to the subjective plane. It questions the contradictory social relations of production and also the productive forces in art and in Culture Industry based in the theories of Marx, Adorno and Horkheimer. It establishes that Brazilian television, bound with late Capitalism, is an 
object which rational processing operates not only in terms of culture reproduction, but, fundamentally, in its own production by the configuration of the viewers. In this sense, this essay discusses the limits and possibilities of formative and educational processes mediated by television.

Keywords: Education; Cultural industry; Television.

Resumen El texto discute cómo la violencia del capital se materializa na televisión, como un todo, y de la serie televisiva $O$ Mecanismo de José Padilha. El autor/director, al establecer en $O$ Mecanismo la corrupción como el "cáncer" de la sociedad capitalista, intencionadamente, elige algo subjetivo, de la moral, como causa de condiciones desiguales de la sociedad del capital, desplazando con intento o no las determinaciones sociales objetivas para el plan subjetivo. Problematiza as relaciones contradictorias entre las relaciones sociales de producción y las fuerzas productivas en el arte y en la industria cultural respaldado en las contribuciones teóricas de Marx, Adorno y Horkheimer. Postula que, el caso de la televisión brasileña entrelazada con o capitalismo tardío, es un objeto cuyo método de razón actúa no solamente en la esfera de la reproducción cultural, sino también, y fundamentalmente, en su producción por medio de la formación del público. En este sentido, analiza os limites y las posibilidades de los procesos formativos y educativos de la televisión.

Palabras clave: Educación; Industria cultural; Televisión.

\section{INTRODUÇÃo}

Convém esclarecer inicialmente que a ambiguidade do título deste trabalho é proposital, porque nele se desvela como o procedimento (ir)racional da (re)produção do capital se objetiva na televisão. Considerada como emblema da indústria cultural, nos termos das análises e reflexões de Adorno e Horkheimer, a televisão se correlaciona às categorias marxianas de relações sociais de produção e de forças produtivas na arte e na indústria cultural. Com base nesses conceitos, pretende-se desvelar como esse mesmo mecanismo se encarna n'O Mecanismo, ${ }^{1}$ de José Padilha. Daí, este texto se propõe a pensar os limites e as possibilidades dos processos formativos e educativos da televisão, tendo como categoria de análise central a maneira como a violência do capital se objetiva "nesses mecanismos". Segundo Adorno e Horkheimer:

Se, em nossa época, a tendência social objetiva se encarna nas obscuras intenções subjetivas dos diretores gerais, estas são basicamente as dos setores mais poderosos da indústria: aço, petróleo, eletricidade, química. Comparados a esses, os monopólios culturais são fracos e dependentes. Eles têm de se apressar em dar razão aos verdadeiros donos do poder, para que sua esfera na sociedade de massas [...] não seja submetida a uma série de expurgos. [...] A unidade implacável da indústria cultural atesta a unidade em formação política (ADORNO; HORKHEIMER, 2006, p. 100).

Série televisiva da Netflix, que estreou sua primeira temporada com oito episódios, em 23/03/2018. 
Embora tenham sido publicadas em 1947, essas constatações empíricas permanecem atuais no sentido formal e no sentido crítico. No sentido crítico a violência do capital ainda "se encarna nas obscuras intenções subjetivas dos diretores gerais", constituiu as produções no passado, perpetua-se hoje nas produções contemporâneas, e se projeta, enquanto tendência, ao futuro, constituindo uma unidade de formação política. O sentido irônico contido em "obscuras intenções subjetivas" se reporta à espontaneidade dos diretores como mera aparência imediata na indústria cultural, como sendo a contraface real da abstração despersonificada do capital. Assim, a indústria cultural continua imbricada com os setores mais poderosos do ponto de vista econômico e ideológico. Essa afirmação de Adorno e Horkheimer - na qual os mecanismos de controle, a estrutura total, as exigências dos financiadores e os padrões estabelecidos reduzem forçosamente as possibilidades de autoexpressão de autores e diretores - abala a ilusão de que as produções culturais sejam apenas projeções psicológicas. A imposição dos limites técnicos e a submissão à obra tornam o autor representante do sujeito coletivo por meio de seu trabalho. É o que assevera Adorno: "Estudar os espetáculos de televisão em função da psicologia dos seus autores seria quase o mesmo que estudar os automóveis Ford em função da psicanálise do falecido Sr. Ford" (ADORNO, 1973a, p. 555).

Atuais também no sentido formal. Hoje, com a ocorrência da revolução digital microeletrônica a TV sob demanda (streaming) está disponível pela web em TVs, computadores de mesa, laptops, tablets e smartphones; ou seja, consumo de seus produtos em qualquer lugar e a qualquer hora, tudo ganhou agilidade. Com o streaming, a venda de conjuntos de produtos resolve melhor um problema antigo da TV tradicional, a coleta e a análise de dados sobre os hábitos de milhões de consumidores. E se tais dados permitem indicar aos clientes programas de TV, séries e filmes que têm alta chance de cair no gosto deles, oferecem, principalmente, a base material para a organização econômica e da produção, aumentando as possibilidades de controle de produções, outrora dominadas por mercados nacionais específicos. Atestando a atualidade do conceito, pois os esquemas capitalistas da indústria cultural em geral, e da TV sob demanda em específico não se contrapõem à constatação de Adorno e Horkheimer. Os setores mais poderosos econômica e ideologicamente são agora os proprietários formais da indústria cultural contemporânea, capitaneados pela abstração despersonificada do capital financeiro, que corporifica a própria dinâmica empírica do capital nos processos de centralização e concentração. As aquisições de jornais, revistas, portais de internet, rádios e televisões, estúdios cinematográficos e serviços de telefonia - por parte de instituições financeiras, indústrias petrolíferas, de telecomunicações, elétricas, eletrônicas e metalúrgicas, fabricantes de armas e de satélites - atestam a relação intestina entre o poder econômico e ideológico dessas megaempresas transacionais e a indústria da cultura. ${ }^{2}$

Um emblema que se reporta às constatações empíricas anteriores é a atuação da BlackRock, uma corporação de investimentos que possui ativos da ordem de US\$ 6 trilhões,

2 Nessa mesma direção ver Chaui (2006) e Duarte (2008). O último faz importante comparação entre a indústria cultural "clássica" e a atualmente denominada "global". 
segundo The New York Times. ${ }^{3}$ Esse capital é cerca de quatro vezes maior que o valor do PIB brasileiro (que, em 2017, totalizou R\$ 6.559,9 bilhões). ${ }^{4}$ De acordo com o jornalista Brian Mier, ${ }^{5}$ a BlackRock é uma das maiores acionistas da Netflix ${ }^{6}$ e sócia majoritária de duas empresas petrolíferas, a Shell e a Chevron.

Em entrevista ao jornal O Globo, ${ }^{7}$ José Padilha atualiza e repõe, pela "inocente" negativa, as análises de Adorno e Horkheimer, já transcritas. Ao ser indagado sobre a origem do financiamento da referida série, respondeu: "Não posso falar, mas será um único financiador, de fora do país. E, como o dinheiro vem de fora, não traz viés político". ${ }^{8}$ Não se trata apenas de contrapor as declarações entre os intelectuais e o autor/diretor, mas sobretudo de realçar a adesão "ingênua" ao pensamento comum de que o dinheiro não tem pátria, não tem língua, não tem ideologia, não faz política e, portanto, não é violento.

A violência do capital, segundo Marx, não tem caráter extraeconômico. Ou, pelo menos, apenas excepcionalmente o é. Ao se referir à transição do feudalismo ao capitalismo, à acumulação primitiva do capital e à transformação do dinheiro em capital, Marx situa a gênese violenta entre as duas classes sociais:

O que faz época na história da acumulação primitiva são todos os revolucionamentos que servem de alavanca à classe capitalista em formação: sobretudo, porém, todos os momentos em que grandes massas humanas são arrancadas violentamente de seus meios de subsistência e lançadas no mercado de trabalho como proletários livres como pássaros (MARX, 1985a, p. 263 - grifos do autor). ${ }^{9}$

A violência do capital objetivada na indústria cultural da qual Padilha se serve é a tentativa de negar a contradição da realidade, ao submeter o real às determinações do capital. O autor/diretor, ao estabelecer n'O Mecanismo a corrupção como o "câncer" da sociedade capitalista, delega ao plano das relações intersubjetivas a possibilidade da prosperidade e do bem-estar da sociedade, de uma suposta ordem e harmonia social. Assim, a política econômica capitalista propicia ubiquamente a democratização da igualdade e da liberdade, mas é impedida pelos indivíduos corruptos. Em face disso, o autor/diretor trabalha para manter intacto o capitalismo ao criar a ilusão da sua não contradição. "Sua vitória [da in-

3 Disponível em: https://www.nytimes.com/2018/01/16/business/dealbook/blackrock-fink-social-good.html. Acesso em: 7 abr. 2018.

4 Disponível em: https://agenciadenoticias.ibge.gov.br/agencia-noticias/2013-agencia-de-noticias/ releases/20166-pib- avanca-1-0-em-2017-e-fecha-ano-em-r-6-6-trilhoes.html. Acesso em: 4 abr. 2018.

5 Disponível em: http://www.abjornalistas.org/page.php?news=5153. Acesso em: 2 abr. 2018.

6 "O montante aplicado pela Netflix em produção própria saiu de 2,5 bilhões de dólares, em 2013, para 6 bilhões, no ano de 2017, segundo o jornalista Eduardo Salgado, na revista Exame. Disponível em: https:// exame.abril.com.br/revista-exame/como-a-revolucao-do-streaming-mudou-os-negocios-das-tvs/. Acesso em: 25 abr. 2019.

7 Disponível em: https://oglobo.globo.com/cultura/filmes/da-policia-politica-jose-padilha-vai-filmar-serie-inspirada-na-lava-jato-19041117. Acesso em: 7 mar. 2018.

8 Nos créditos da série, encontra-se escrita a seguinte frase: "Uma produção original da Netflix".

9 Esses grifos têm a intenção de realçar a ironia de Marx. 
dústria cultural] é dupla: a verdade, que ela extingue lá fora, dentro dela pode reproduzir a seu bel-prazer como mentira" (ADORNO; HORKHEIMER, 2006, p. 111).

Esses mecanismos podem ser desvelados mediante o diálogo entre Adorno e Horkheimer e Marx (2008), na compreensão de que as contradições entre as relações sociais de produção capitalistas e suas forças produtivas configuram a distinção entre arte e indústria cultural. Como se vê, é atributo da arte problematizar a contradição da realidade, pois nela as forças produtivas se emancipam relativamente das relações sociais de produção e se contrapõem à indústria cultural. Nesta, as forças produtivas se submetem às relações de produção. Com isso, o trabalho da indústria cultural é o de obliterar as contradições da realidade, de sustentar determinada forma de sociedade, de (re)produzir as condições concretas da realidade sem problematizá-las. Essa distinção entre arte e indústria cultural, nesses termos, será necessária para discutir uma questão: $O$ Mecanismo é arte ou produto da indústria cultural $?^{10}$

Ao recapitular as categorias de análise requeridas - o mecanismo da objetivação da contradição entre relações sociais capitalistas e as forças produtivas na arte e na indústria cultural -, é possível esclarecer se O Mecanismo é arte ou produto da indústria cultural. Afinal, segundo Adorno:

...pela revelação das implicações sóciopsicológicas e dos mecanismos da televisão, que frequentemente operam sob a máscara do falso realismo, não somente se podem melhorar os espetáculos, mas também, o que é talvez mais importante, será possível sensibilizar o público em geral para os efeitos de alguns desses mecanismos (ADORNO, 1973a, p. 546).

Assim, a "função" da indústria cultural é impedir que a violência do capital sobre o trabalho seja desvelada, contribuindo para o não esclarecimento das contradições da sociedade dividida em classes e não problematizando as implicações do ponto de vista educativo dessa produção. É o que a análise e a crítica a seguir pretendem demonstrar.

\section{O PRIMEIRO MECANISMO}

A determinação universal do trabalho, da objetivação, toma formas diferentes nos desenvolvimentos particulares históricos, nos diversos modos de produção. Segundo Marx, no prefácio da Contribuição à crítica da economia política, a totalidade das relações sociais de produção constitui a estrutura econômica da sociedade, a base concreta que corresponde determinadas formas de razão e de sociabilidade. Objetivamente, as condições materiais de existência condicionam um modo de internalização individual e emocional constituindo a subjetividade, definindo um mecanismo específico de subjetivação das con-

10 Evita-se conscientemente a relação entre arte e mercadoria, pois seria necessário problematizar, por exemplo, a afirmação de Adorno e Horkheimer: "É assim que o caráter mercantil da obra de arte se desfaz ao se realizar completamente" (ADORNO; HORKHEIMER, 2006, p. 131). Para os autores, na sociedade do capital tudo é mercadoria, inclusive a arte. Discutir, entretanto, o problema da arte excede os limites deste texto. 
dições concretas, ou seja, estabelecendo uma forma de razão. A determinação histórica do sujeito - a condição do ser social - estabelece a constituição do sujeito individual, da subjetividade: "O modo de produção da vida material condiciona o processo da vida social, política e intelectual. Não é a consciência dos homens que determina o seu ser; é o seu ser social que, inversamente, determina a sua consciência" (MARX, 2008, p. 45).

Para Marx (2010a), a alienação - a dissociação entre os trabalhos concreto e abstrato, inerente à objetividade humana - se constitui em uma forma histórica específica na produção das mercadorias na sociedade capitalista, uma consequência dos nexos distintivos entre os processos das forças produtivas e os movimentos das relações sociais de produção. Nessa sociedade, é o capital - a propriedade privada dos meios de produção - que configura as formas desse modo de produção. Ou seja, as relações sociais de produção. ${ }^{11}$ Os seres humanos, as ferramentas, as máquinas, os elementos dos processos das forças produtivas, tudo isso é aparentemente dissociado dos movimentos das relações de produção: as relações sociais entre assalariados, entre capitalistas e entre assalariados e capitalistas. No capitalismo, é o trabalho, como nos outros modos de produção, que configura as forças produtivas e determina como se estabelecem os relacionamentos entre os elementos dos processos dessas forças. No entanto, são as relações de produção determinadas pelo capital que definem os elementos, suas relações e os processos das forças produtivas.

$\mathrm{Na}$ sociedade da aparente livre concorrência, cria-se e se recria a ilusão funcionalmente necessária do sujeito aparentemente isolado da natureza e dos outros homens. Esse sujeito isolado, responsável único pelo próprio sucesso e/ou fracasso mediante suas relações intersubjetivas, figura como dono de sua história, como seu ponto de partida, como resultado da natureza humana, mas não das condições sócio-históricas. Para Marx (2010a, p. 86), se o trabalho e o produto do trabalho não pertencem ao trabalhador, cabe a outro homem, ao proprietário dos meios de produção. Daí, a separação entre o trabalhador e o trabalho é efetiva, pois, ao venderem sua força de trabalho, os sujeitos se vendem. Suas vidas, externadas na produção de mercadorias, que não lhes pertencem e nas quais não se reconhecem, separam-nos da sua produção, escapando deles sua objetivação e sua subjetividade. Aí está a funcionalidade da referida ilusão, criar e recriar obstáculos para o esclarecimento da alienação.

A realidade do processo de produção capitalista para a troca de mercadorias, que abstrai os trabalhos e os trabalhadores e tende a torná-los equivalentes, autonomiza os indivíduos, cria a ilusão da igualdade burguesa e obscurece a natureza social do trabalho. A racionalidade de dominação do capital esconde, camufla e preserva a tendência irracional da sociedade do capital de autonomização entre sociedade e indivíduo. Desse modo, fica clara a tendência de considerar sociedade e indivíduo como realidades distintas e autônomas entre si. Ocultando a contradição da realidade, essa racionalidade de dominação irracional se produz e se reproduz mediada pelos processos educativos formais e informais. A formação para o trabalho e para a sociabilidade impede objetiva e subjetivamente as possibilidades

11 "O capital também é uma relação social de produção. É uma relação burguesa de produção, uma relação de produção da sociedade burguesa" (MARX, 2010b, p. 46; grifos no original). 
de reconhecimento da dimensão social do trabalho. Segundo Adorno e Horkheimer, "Na sociedade moderna, a técnica já adquiriu uma estrutura e uma posição específicas, cuja relação com as necessidades dos homens é incongruente. Assim, o mal não deriva da racionalização do nosso mundo mas da irracionalidade com que essa racionalização atua" (ADORNO; HORKHEIRMER, 1973b, p. 98).

Entretanto, contraditoriamente, os próprios mecanismos dos processos educativos e formativos da irracionalidade de dominação do capital mobilizam objetiva e subjetivamente o reconhecimento da dimensão social do trabalho. Afinal, tais mecanismos não reinam incontestes. $\mathrm{O}$ esclarecimento da alienação constitutiva do modo de produção capitalista permite a compreensão dos mecanismos educativos e formativos da alienação social. Nesse sentido, a arte se oferece como possibilidade de esclarecimento, de conhecimento, de expressão, de reconhecimento humano e, portanto, de emancipação. Afinal, a arte é não só uma mediação psicossocial no processo de formação humana, mas também conhecimento. Nesses termos, pergunta-se: $O$ Mecanismo de José Padilha é arte?

$\mathrm{Na}$ Introdução à contribuição à crítica da economia política, Marx afirma:12 "quanto à arte, já se sabe que os períodos de florescimento determinados não estão, absolutamente, em relação com o desenvolvimento geral da sociedade, nem, portanto, com a base material, o esqueleto, de certo modo, de sua organização" (MARX, 2008, p. 268). Marx ressalta e, nesse sentido, resguarda a arte em sua autonomia relativa no tocante às relações de produção, à base material da sociedade. E o faz quando se refere aos "períodos de florescimento" da arte, indicando e especificando os limites da relação contraditória entre as forças produtivas e as relações de produção na arte.

Na relação contraditória das forças produtivas com as relações de produção são estas que quase sempre constituem o momento predominante da relação. Mas nos "períodos de florescimento" da arte, as suas forças produtivas não estão absoluta e imediatamente determinadas pelas relações sociais de produção, e, ao mesmo tempo, testemunham sempre essa contradição. Para Marx, "A arte grega pressupõe a mitologia grega, isto é, a natureza e a própria sociedade modelada já de uma maneira inconscientemente artística da natureza (compreendendo essa última tudo que é objeto, logo, também, a sociedade)" (MARX, 2008, p. 269) ${ }^{13}$ Nos períodos revolucionários, as forças produtivas se desenvolvem mais na lógica da ruptura, sempre relativa, com as relações sociais de produção, do que no sentido da continuidade dessas. Em contrapartida, os momentos de continuidade são aqueles em que as relações de produção determinam as forças produtivas, razão pela qual o sentido delas é de manutenção e conservação das relações de produção.

12 A par das inúmeras referências as artes (ver especialmente carta de Marx ao pai em HEINRICH (2018, p. 425) e a compilação de trechos de Marx e Engels em Sobre literatura e arte, editada em Portugal por Editorial Estampa em 1971), esta passagem com outra, no Capitulo VI inédito de O Capital; resultados do processo de produção imediata (1985b, p. 115-119), parecem os únicos escritos críticos de Marx sobre o tema. Inclusive, na última, Marx entrevê a possibilidade de a produção artística ser atingida pela forma mercadoria.

13 Parece que Marx, ao colocar entre parênteses esse adendo, quer dirimir qualquer possibilidade de ser interpretado equivocadamente. Nas relações contraditórias entre as condições objetivas e as subjetivas, aquelas, e não estas, constituem sempre historicamente o momento predominante. 
Em outra passagem, Marx é mais explícito sobre a contradição entre as relações de produção e as forças produtivas no campo da arte. Marx se refere à arte como sendo determinada pelas relações de produção e indica os momentos de continuidade:

\begin{abstract}
Em relação a certos gêneros de arte, a epopeia, por exemplo, admite-se que jamais podem produzir-se em sua forma clássica, fazendo época no mundo, desde o momento em que a produção artística aparece como tal; isto é, no interior do domínio da própria arte, algumas manifestações importantes não são possíveis senão em um grau inferior da evolução da arte. Se isso é certo, referindo-se à relação dos diferentes gêneros de arte no interior do domínio da própria arte, não se pode estranhar que também o seja a respeito da relação do domínio todo da arte com o desenvolvimento geral da sociedade (MARX, 2008, p. 268). ${ }^{14}$
\end{abstract}

Convém distinguir aqui duas perspectivas históricas que se articulam, pois se referem a contextos distintos. Embora em ambos os contextos, ao afirmar "no domínio da própria arte", Marx esteja se referindo às forças produtivas e, ao mesmo tempo, objetivamente às relações de produção como o momento determinante no nexo com as forças produtivas. No primeiro contexto, a distinção é mais restrita, pois Marx se refere aos contextos históricos específicos, relacionando cada modo de produção com sua expressão artística. No segundo contexto, mais genérico, menciona a condição universal da arte, "do domínio todo da arte com o desenvolvimento geral da sociedade", destacando, assim, as relações contraditórias entre as forças produtivas e as relações de produção ao longo da história da civilização.

Pode-se, nessas bases conceituais, relacionar a indústria cultural à arte. Para Adorno e Horkheimer (2006, p. 100), a indústria cultural (re)produz a lógica da racionalidade dominante, constituinte da formação de uma unidade política, da continuidade dos valores éticos e estéticos atuais da sociedade, que reprime suas forças produtivas. Daí, o capital violentamente submete o trabalho a sua lógica, e "se encarna nas obscuras intenções subjetivas dos diretores".

Na indústria cultural, embora a contradição entre as forças produtivas e as relações sociais se mantenha, como na arte, naquela, diferente dessa, há uma subordinação das forças produtivas às relações sociais de produção, na determinação do conteúdo e da forma ${ }^{15}$ da indústria cultural. Ou seja, na indústria cultural, como Adorno e Horkheimer a sintetizam,

14 Não se pode inferir, equivocadamente, que Marx esteja fazendo juízo de valor, ou seja, estabelecendo hierarquia entre os gêneros artísticos. Sua discussão não é nesse campo. Interpretado sob essa perspectiva, pode- se entender que, para Marx, a epopeia é um grau inferior de arte, mas isso contrariaria o próprio Marx, que em outra passagem no referido texto afirma: "O difícil não é compreender que a arte grega e a epopeia se achem ligadas a certas formas de desenvolvimento social, mas que ainda possam proporcionar gozos estéticos e sejam consideradas em certos casos como norma e modelo inacessíveis" (MARX, 2008, p. 269).

15 Para mais esclarecimentos sobre a relação entre o conteúdo e a forma, é importante refletir sobre o seguinte trecho: "A dificuldade em isolar a forma é condicionada pelo entrelaçamento de toda a forma estética com o conteúdo; deve ser concebida não só contra ele, mas através dele. [...] O formato, o conteúdo, não são objetos exteriores à forma, mas impulsos miméticos arrastados para esse mundo das imagens que é a forma [...], a qual é devida ao conteúdo, é em si mesma um conteúdo sedimentado" (ADORNO, 2008, p. 15). 
as forças produtivas a ela atadas não rompem e não possibilitam a problematização das relações sociais de produção, testemunhando apenas essa subordinação:

\begin{abstract}
O terreno no qual a técnica [as forças produtivas] conquista seu poder sobre a sociedade é o poder que os economicamente mais fortes exercem sobre a sociedade. A racionalidade técnica hoje é a racionalidade da própria dominação. Ela é o caráter compulsivo da sociedade alienada de si mesma (ADORNO; HORKHEIMER, 2006, p. 100).
\end{abstract}

De modo diferente, a arte pode expressar sua autonomia relativa na contradição, porque suas forças produtivas permitem, sobretudo "em períodos de florescimento", romper com as condições sociais, atestando com isso a possibilidade de existência de outras formas de organização social. Isso não ocorre na indústria cultural nem na televisão, em particular. As expressões de ruptura na televisão são, quase sempre, apenas formais e não estruturais, mas tão-somente manifestações de conteúdo reformista de sua própria racionalidade.

Relacionar a arte à televisão é, do ponto de vista heurístico, importante para a análise e a crítica empírica da televisão, que, apesar de fundamentais para estabelecer o valor qualitativo de cada produção específica, são limitadas. Cabe estender a análise e a crítica às relações sociais de produção da televisão como uma totalidade social, sob pena de se limitar a crítica ao dissociá-la do contexto histórico. Afinal, são as relações sociais de produção que determinam não só a produção televisiva, mas também a forma de experiência com essa produção.

De modo geral, conforme Adorno e Horkheimer (2006), a razão objetiva do capital, sua (ir)racionalidade, seus mecanismos não são mostrados pela televisão, embora as organizem e as administre. Com isso, (de)forma-se a capacidade de compreensão da realidade pelo público, que não mostra a desrazão do capital, apenas sua razão. Para Adorno e Horkheimer, o estilo de naturalidade e espontaneidade que em algumas produções a realidade exterior é transferida para dentro das obras da indústria cultural impede e/ou obstrui a imaginação e a liberdade, na medida em que se compromete a apagar as fronteiras entre a realidade e as obras, entre a realidade e a ficção tornando-a uma continuidade daquela. ${ }^{16}$ Assim, acontece na experiência com a televisão o mesmo que com o cinema industrial:

\footnotetext{
O mundo inteiro é forçado a passar pelo filtro da indústria cultural. A velha experiência do espectador do cinema, que percebe a rua como um prolongamento do filme que acabou de ver, porque este pretende ele próprio reproduzir rigorosamente o mundo da percepção cotidiana, tornou-se a norma da produção. Quanto maior a perfeição com que suas técnicas duplicam o mundo exterior é o prolongamento sem ruptura do mundo que se descobre no filme. [...] e é assim precisamente que o filme adestra o espectador entregue a ele para se identificar imediatamente com a realidade (ADORNO; HORKHEIMER, 2006, p. 104).
}

16 Nesse sentido, ver o trabalho de Rondelli (1997). 


\section{O SEgUNDO MECANiSMo: O DA TELEVISÃo ENCARNADO N'o MECANISMo}

N’O Mecanismo, de José Padilha, a violência do capital não é problematizada. É apenas um pano de fundo, uma paisagem abstrata, uma natureza morta, apesar de ser muito concreta e viva. Há uma naturalização dos processos sociais: aquilo que é história, produto do desenvolvimento humano, é mostrado como algo "naturalmente" humano. O capitalismo é objetivado como se fosse o desenvolvimento natural do humano, sem apresentar contradições. N'O Mecanismo se objetiva aquilo que Marx denomina como "a muda coação" formadora da (ir)racionalidade do capital:

\footnotetext{
Não basta que as condições de trabalho apareçam num pólo como capital e no outro pólo, pessoas que nada têm para vender a não ser sua força de trabalho. Não basta também forçarem-nas a se venderem voluntariamente. Na evolução da produção capitalista, desenvolve-se uma classe de trabalhadores que, por educação, tradição e costume, reconhece as exigências daquele modo de produção como leis naturais e evidentes. A organização do processo capitalista de produção plenamente constituído quebra toda a resistência, a constante produção de uma superpopulação mantém a lei da oferta e da procura de trabalho e, portanto, o salário, em trilhos adequados às necessidades de valorização do capital, e a muda coação das condições econômicas sela o domínio do capitalista sobre o trabalhador. A violência extra-econômica direta é ainda, é verdade, empregada, mas apenas excepcionalmente. Para o curso usual das coisas, o trabalhador pode ser confiado às "leis naturais da produção", isto é, à sua dependência do capital que se origina das próprias condições de produção, e por elas é garantida e perpetuada (MARX, 1985, p. 277).
}

A série de José Padilha trabalha para obliterar a violência da submissão do trabalho ao capital, e o autor/diretor o faz mediante a centralização da corrupção, como o "câncer" a ser combatido. A elegia, centrada em certos indivíduos autônomos e isolados - como modelo de comportamento capaz de reconfigurar as relações sociais -, canaliza a reação do público e repõe duas dimensões da ideologia do capitalismo criticado por Marx. A primeira se refere à ilusão funcionalmente necessária da dicotomia e ao antagonismo entre o indivíduo e a sociedade, que surge como estruturante do mecanismo de produção e reprodução da sociedade burguesa. A segunda dimensão se reporta à ilusão articulada com a primeira, que tenta negar as forças produtivas como predominantemente determinadas pelas relações sociais de produção, conferindo àquelas uma suposta autonomia perante estas.

Objetivar as forças produtivas como possibilidade de reconfigurar as relações de produção, valorizar o trabalho de um indivíduo pretensamente autônomo capaz de requalificar as relações sociais, é "função" da indústria cultural. Os produtores, autores e diretores da indústria da cultura, como agentes do capital, emulam tais ilusões intencionalmente ou não em razão de manter, sustentar e conservar as relações de produção, implicando o indivíduo.

Para Adorno e Horkheimer, essa particularização das questões objetivas não é atribuição do pensamento subjetivista dos produtores da televisão, de igual modo, é produção 
ordenada pela (ir)racionalidade instrumentalizada, pragmática e utilitária. A objetivação de personagens, como encarnações das forças produtivas, mais ou menos capazes que outros, como se as capacidades não fossem determinadas nas condições históricas, mas aparentemente fossem intrínsecas aos indivíduos, produz as condições de apropriação, de entendimento desses personagens. $\mathrm{O}$ espectador que se identifica e se forma com e nessa particularização tende a se conformar com a aparente dissociação entre indivíduo e sociedade, entre as forças produtivas e as relações de produção. E nesse movimento mantém-se adaptado à aparente autonomização da organização social sob o domínio do capital.

Nesse sentido, os autores criticam o argumento de que os padrões éticos e estéticos da indústria da cultura são originários das necessidades dos consumidores e que, por isso, são aceitos sem resistência. Ao contrário, para os autores, são aceitos sem resistência porque fecham o círculo da necessidade retroativa entre a produção e a demanda. A produção, na sua origem, não é apenas formatada ao público a que se destina, mas produz as necessidades nos consumidores. $\mathrm{O}$ espectador já está impedido, pela característica da própria produção, por meio da expropriação do esquematismo kantiano de referenciar racionalmente o personagem, o enredo, o drama à universalidade, às questões objetivas. ${ }^{17}$

Para o consumidor, não há mais nada a classificar que não tenha sido antecipado no esquematismo da produção. A arte sem sonho ${ }^{18}$ destinado ao povo realiza aquele idealismo sonhador que ia longe demais para o idealismo crítico (ADORNO; HORKHEIMER, 2006, p. 103).

Os padrões de entendimento dos personagens já estão ordenados, e ao tentar-se destituí-los de universalidade, (re)produz-se a falsa e ilusória autonomia dos indivíduos, abstraindo suas particularidades e exortando-se uma experiência subjetivista.

Kant antecipou intuitivamente o que só Hollywood realizou conscientemente: as imagens já são pré-censuradas por ocasião de sua própria produção segundo os padrões do entendimento que decidirá depois como devem ser vistas. A percepção pela qual o juízo público se encontra confirmado já estava preparada por ele antes mesmo de surgir (ADORNO; HORKHEIMER, 2006, p. 73).

Como exemplo desses padrões de entendimento imbrincado às produções, da apropriação do esquematismo kantiano, a indústria cultural já fabrica a resolução de conflitos, como se fosse possível resolvê-los no plano das relações particulares, sejam esses conflitos nacionais, globais, regionais ou familiares, ou até mesmo os próprios conflitos individuais, sejam as contradições reais entre as classes sociais, entre indivíduo e sociedade. Os conflitos e as contradições são objetivados seguindo a ordem social vigente e foram estabeleci-

17 Conforme reflexão de Duarte (2003a, 2003b, 2008). Nos três artigos Duarte desvela tanto o contexto teórico em que surge a doutrina do esquematismo em Kant, quanto relaciona outras referências nos textos de Adorno e Horkheimer para a compreensão dessa apropriação do esquematismo.

18 Essa referência da arte sem sonho é explicitada, no que diz respeito especificamente à televisão, no ensaio Televisão, consciência e indústria cultural, de autoria de Adorno (1977a, p. 346). 
dos por meio dos padrões dessa racionalidade subjetiva, assim como o foram as formas e os modos pelos quais devem ser compreendidos e resolvidos.

No caso em questão, Ruffo, ${ }^{19}$ que representa idealmente todos nós, encarna as forças produtivas e nosso trabalho no combate à corrupção. Objetivamente, porém, Ruffo trabalha para manter as coisas como são. Ele é o objeto estereotipado de que necessitamos para suportar nossa impotência diante da violência do capital. Como Sísifo, ele exibe e repete incansavelmente a autonomia do trabalho humano individualizado, interminável e inútil, para que a sujeição ao capital não seja explicitada e não se torne consciente. Conforme Adorno:

\begin{abstract}
É de se supor que a televisão faz delas [as pessoas] mais uma vez aquilo que de qualquer forma já são, só que ainda mais do que já o são. Isso corresponderia à tendência global, de base econômica, da sociedade contemporânea, no sentido de não ir mais além de si próprio em suas formas de consciência, mas sim de reforçar tenazmente o status quo e sempre que ele pareça ameaçado, reconstruí-lo. A tensão sob a qual as pessoas vivem cresceu a tal ponto, que elas não a suportariam se as realizações adaptativas que uma vez conseguiram não lhes fossem exibidas e não repetissem nelas sempre de novo. Freud ensinou que a repressão dos impulsos jamais tem êxito total nem definitivo, e que por isso a energia psíquica inconsciente do indivíduo é incansavelmente desperdiçada para manter no inconsciente aquilo que não deve assomar ao consciente. Esse trabalho de Sísifo da economia psíquica individual parece estar hoje "socializado", tomado a seu cargo pelas instituições da indústria cultural, para benefício das instituições e dos poderosos interesses que lhe estão por detrás. Para isso contribui a televisão, tal como é. Quanto mais completo o mundo como aparência, tanto mais inescrutável a aparência como ideologia (ADORNO,1977a, p. 347).
\end{abstract}

A série se ocupa de informações pobres e insignificantes porque são simplórias, de padrões de comportamento conformistas com ares de rebeldia, de relações políticas elementares e superficiais. Nela se expõem apenas os conflitos que podem ser resolvidos mediante o trabalho de indivíduos supostamente livres e autônomos. No pano de fundo está o conformismo com a ordem capitalista estabelecida; as relações sociais de produção não são sequer mencionadas, apenas o são as forças produtivas. Afinal é apenas a corrupção em todos os níveis da esfera da política pública que, caso se extinga, promove a ilusória harmonia da ordem capitalista. É emblemático que Ruffo entenda o mecanismo a partir da corrupção entre um funcionário público encarregado dos esgotos e uma empresa prestadora de serviços. Esse personagem, por não ser corrupto, representa todos nós no imaginário; ele pode não apenas criticar a corrupção como se torna um modelo a ser seguido por todos. O sentido de esclarecimento, o desvelamento da realidade que a série ilusoriamente parece propiciar faz exatamente o contrário: encobre e vela ainda mais as contradições da realidade. Este é o seu trabalho: velar a realidade.

19 Esse personagem é a representação ficcional do delegado da Polícia Federal Gerson Machado, que afirma ser o autor do inquérito que, em 2008, reuniu informações de que o Posto da Torre, em Brasília, era usado para lavagem de dinheiro por meio da emissão de notas frias. O esquema só ficou conhecido em março de 2014, quando foi deflagrada a Operação Lava-Jato. 
A afirmação categórica de que é ancorada em fatos reais revela que há intencionalmente uma introdução de dados e fatos na realidade. Os acontecimentos são retratados com tamanha proximidade da realidade, aos moldes de um documentário. As ações dos personagens são tão correlatas ao cotidiano como uma duplicata do mundo empírico. Não há tempo na narrativa para a imaginação e a reflexão. O mundo retratado é apenas o mundo tal como se apresenta a um sujeito empírico, impossibilitando, ou pelo menos dificultando, o distanciamento e a crítica da totalidade da realidade. Tudo na trama se desenvolve na ordem do cotidiano de Ruffo. Nada lhe escapa, afinal tudo é absolutamente superficial, mas com ares profundos. A ingenuidade latente de Ruffo só é expressa como inteligência porque as questões com as quais ele tem de lidar são absurdamente ingênuas. Segundo Adorno, "Dificilmente será ir longe demais dizer que, reciprocamente, a realidade é olhada através dos óculos da TV, que o sentido furtivamente imprimindo ao cotidiano volte a refletir-se nele" (ADORNO,1977a, p. 349). Objetivamente, ao se declarar que é baseada em fatos reais, a série cumpre a função de se exibir como uma crítica apenas ao aparente e, ao mesmo tempo, de se conformar com o oculto. Ou seja, as condições concretas da realidade são objetivadas, mas não problematizadas; ficam veladas e tendem a fixar padrões de comportamento conformistas ou no máximo reformistas sem que se tenha consciência disso. Nas palavras de Adorno:

A relação entre a mensagem manifesta e a oculta se revelará altamente comple-
xa na prática. Assim, a mensagem oculta visa com frequência a reforçar atitudes
convencionalmente rígidas e "pseudo-realísticas" semelhantes às idéias aceitas,
mais racionalisticamente propagadas pela mensagem de superfície. Inversa-
mente, permite-se a certo número de satisfações reprimidas, que desempenham
um papel de relevo no nível oculto, manifestar-se à superfície, traduzidas em
gracejos, observações ambíguas, situações sugestivas e artifícios semelhantes.
Toda essa interação de vários níveis, entretanto, indica uma direção definida: a
tendência de canalizar a reação do público. Isto se coaduna com a suspeita am-
plamente partilhada, embora difícil de ser confirmada por dados exatos, de que
a maioria dos espetáculos de televisão objetiva hoje produzir ou, pelo menos,
reproduzir, a fatuidade, a passividade intelectual e a ingenuidade que parecem
ajustar-se aos credos totalitários, ainda que a explícita mensagem de superfície
dos espetáculos seja antitotalitária (ADORNO, 1973a, p. 552).

Ruffo tenta simbolizar todos nós, mas, ao mesmo tempo, apenas a ele é dada a oportunidade de realizar a violência purificadora, de manifestar a satisfação reprimida, de espiar o ódio particular, comum a todos nós, contido na repressão necessária à civilização. Legitima a violência com as próprias mãos. A falta de escrúpulos, disfarçada de caráter obsessivo, solitário, violento (sempre em associação com o bem), estimula o elemento primário do ser humano, o instintivo, o passional. É contraditoriamente o mais superficial e o mais profundo. Ruffo sozinho interfere nas investigações institucionais, "planta" um amigo no interior da equipe da "Polícia Federativa" para atuar como seus olhos e ouvidos, mas principalmente para falar e agir por ele. Ademais, ameaça pessoas com revólver, assedia prisioneiros, 
acessa documentos sigilosos, chafurda ilegalmente no lixo de seu inimigo, desacata promotores de justiça e juízes. Enfim, comete ilícitos que tornam a operação possível. Resta-lhe como personagem ficcional conduzir e fazer todo serviço sujo que a narrativa oficial da Lava-Jato não mostra.

Ruffo personaliza ao mesmo tempo tanto a impotência do ser humano comum quanto a idealização de um super-humano autodeterminado acima das leis e da ética. É com essa ambivalência que o personagem se objetiva. ${ }^{20}$ Se de um lado podemos nos identificar com a sua prosaica vida comum de um trabalhador, conforme as palavras de Ruffo (nota-se que o personagem deveria dizer Polícia Federativa mas enuncia Polícia Federal): “20 anos de Polícia Federal deu pra comprar um carro usado para a minha esposa e um sítio no interior do Paraná para garantir o futuro da minha filha". De outro lado, também, pode-se identificar com a sua perda de autocontrole racional e que lhe permite atacar os rígidos padrões do comportamento social, com o sancionamento da expressão de suas emoções e ações à revelia das instituições sociais, o personagem se abandona a toda a sorte de ações se liberando para usar da violência, cria-se uma imagem idealizada por meio da sua onipotência. E "destina-se a perpetuar o indivíduo como se ele fosse independente, submetendo-o ainda mais profundamente a seu adversário, o poder absoluto do capital" (ADORNO; HORKHEIMER, 2006, p. 100).

A série elege algumas formas de corrupção: (i) o desvio de dinheiro público, centrando o foco na classe política e acintosamente relegando a corrupção do mercado; (ii) a sonegação de impostos; (iii) a desregulamentação do mercado financeiro; (iv) a revogação das conquistas históricas das leis trabalhistas; (v) a formação de monopólios; e (vi) a superexploração do trabalho praticada pelas empresas. Todas essas formas são "esquecidas" no debate sobre a corrupção. ${ }^{21}$ Assim, deliberadamente, elege algo da ordem do subjetivo, da moral, como causa das condições desiguais da sociedade do capital, deslocando intencionalmente as determinações sociais objetivas para o plano subjetivo. O ponto de fuga da obra, sua referência externa, é a superação das atuais condições concretas da sociedade brasileira e a melhoria da vida de todos os brasileiros. Para tanto, foca uma das formas de corrupção como único obstáculo. ${ }^{22} \mathrm{E}$, como possibilidade de superação, escolhe alguns indivíduos como representantes da moral e dos bons costumes, aptos a corrigir as mazelas

20 Nesses termos, pode-se relacionar em Adorno a objetivação do personagem Ruffo com um dos dispositivos básicos da propaganda fascista: 'É o conceito do 'pequeno grande homem', uma pessoa que sugere tanto a onipotência quanto a ideia de que é apenas mais um do povo. [...] A imagem do líder [Ruffo] satisfaz o duplo desejo do seguidor em se submeter à autoridade e ser ele mesmo a autoridade" (ADORNO, 2015, p. 172).

21 Os dados colhidos na imprensa desvela a relevância da corrupção brasileira. Segundo pesquisa da FIESP, 69 bilhões de reais foram desviados dos cofres públicos em esquemas de corrupção em 2015. Entretanto, de acordo com o Sindicato Nacional dos Procuradores da Fazenda Nacional, só em 2015 o Brasil deixou de arrecadar R $\$ 500$ bilhões por sonegação de impostos. Ainda mais sintomático é que o governo federal gastou em 2016, em juros e amortizações da dívida pública brasileira, 407 bilhões. Ou seja, pouco menos do que o governo gastou no mesmo ano com a Previdência Social (550 bilhões).

22 A violência como forma de combater a corrupção, e a corrupção nesses termos aqui discutidos, é foco recorrente na produção do autor/diretor, foi também objetivada nos filmes Tropa de Elite 1 e 2, exibidos nos anos de 2007 e de 2010 respectivamente. 
da sociedade. A capacidade de reconfiguração da sociedade desloca-se, portanto, das instituições e das organizações sociais, do indivíduo como ser social, à medida que se centra em certos indivíduos autônomos e isolados. Uma prova disso é que o curso dos acontecimentos na série em análise se desenrola num plano exclusivamente particular e cria uma imagem invertida da realidade. A real impotência das pessoas isoladas perante a sociedade do capital aparece como falsa, ao criar a ilusão de que o trabalho de indivíduos isolados é capaz de transformar a sociedade. A identificação do público com os heróis da trama, em especial com o personagem Marcos Ruffo (Selton Mello), que encarna essa ilusória potência, condiciona o público ainda há uma maior impotência. Ao franquear a indivíduos isolados as possibilidades de superação das precárias condições sociais, o mecanismo d'O Mecanismo é o de educar o público nessa ilusão, é o de esconder que a produção das desigualdades sociais é inerente ao modo de produção capitalista. Nesse sentido, a série repõe perguntas formuladas pelos teóricos da Escola de Frankfurt, principalmente Adorno e Horkheimer: como as mediações institucionais, estruturais e psíquicas que organizam e administram as nossas consciências produzem essa aderência à corrupção como causadora das mazelas sociais? Como impedem, ou, pelo menos, obstaculizam a crítica dessa forma de razão capitalista? Ou seja, como e por quais mediações as pessoas aderem a formas de pensamento e ação que vão contra seus próprios interesses?

A produção capitalista os mantém tão bem presos em corpo e alma que eles sucumbem sem resistência ao que lhes é oferecido. Assim como os dominados sempre levaram mais a sério do que os dominadores a moral que deles recebiam, hoje em dia as massas logradas sucumbem mais facilmente ao mito do sucesso dos bem-sucedidos. Elas têm os desejos deles. Obstinadamente, insistem na ideologia que os escraviza (ADORNO; HORKHEIMER, 2006, p. 110).

O Mecanismo é, nesse sentido, a objetivação da afirmação de Chaui, que, referida ao processo de reificação marxista, indica como o mecanismo violento do capital se faz na televisão:

\footnotetext{
Os meios de comunicação e a ideologia dominante consideram que a violência é idêntica à criminalidade. Identifica violência e delinquência. Violência e criminalidade. Isso não é a violência, isso é um aspecto da violência. A violência significa tratar um ser humano, uma pessoa dotada de razão, vontade, sentimentos, portanto tratar uma subjetividade, um outro sujeito como se ele fosse uma coisa, como se ele não tivesse pensamento, vontade, liberdade, o uso da linguagem, o uso da palavra, o uso da subjetividade, é isso a violência. A violência é reduzir um outro da condição de sujeito à condição de coisa (CHAUI, 2018, s/ p.).
}

\section{CONSIDERaÇões Finais}

Nesses termos, a tendência das megafusões, do crescente acúmulo de capital e de poder da indústria cultural na atualidade determina processos educativos e formativos. Se- 
gundo Adorno, desde sempre ela não apenas fabrica produtos destinados ao consumo, mas também produz sujeitos consumidores para o que ela fabrica: "O consumidor não é o rei, como a indústria cultural gostaria de fazer crer; ele não é o sujeito dessa indústria, mas seu objeto" (ADORNO, 1977b, p. 288). Adorno assim se reporta quando atualiza a mesma racionalidade da (re)produção do capital desvelada por Marx, "A produção não produz, pois, unicamente, o objeto do consumo, mas também o modo de consumo, ou seja, produz objetiva e subjetivamente. A produção cria, pois, os consumidores" (MARX, 2008, p. 246).

Intencionalmente ou não, os personagens da série $O$ Mecanismo são produzidos sob a mesma lógica da (ir)racionalidade do capital. Isso implica aplainar as diferenças culturais e os antagonismos das classes sociais em favor de uma ficção em que as desigualdades sociais não são determinações materiais da exploração do trabalho pelo capital. A televisão brasileira - um emblema lógico e histórico da indústria cultural brasileira, imbricada com o capitalismo tardio - é um objeto cujo procedimento de razão atua não apenas na esfera da reprodução da cultura, mas, fundamentalmente, na sua produção pela via da formação do público. Como a televisão encarna a contradição da realidade, ao mesmo tempo em que sujeita essa contradição à sua racionalidade, sua forma e seu conteúdo estão implicados na instrumentalização do funcionamento social. Em face disso, determina-se uma obstrução na compreensão dessas contradições e dos elementos constituidores da realidade. As questões sociais, quase nunca tratadas em sua complexidade, restam como casos particulares. $\mathrm{O}$ espectador dificilmente, senão in totum, fica impossibilitado de referenciar racionalmente as histórias e os personagens às questões objetivas. Tal procedimento produz e retroalimenta o movimento do Capital e sua tendência de dissociar sociedade e indivíduo como realidades distintas e autônomas entre si, e opera mais além, na valorização do indivíduo supostamente livre em detrimento do indivíduo como ser social.

Assim, os processos educativos mediados pela televisão brasileira condicionam a internalização de seus procedimentos (ir)racionais não críticos - por não serem contraditórios - e favorecem a adesão dos indivíduos aos conjuntos de valores e comportamentos estereotípicos como se fossem construídos a partir de experiências concretas. Ademais, a par da possibilidade contraditória de mediar processos educativos críticos e formativos para se compreender a realidade, a televisão brasileira, em geral, e $O$ Mecanismo, em particular, condicionados por sua forma de produção, são inversamente (de)formativos pela ocultação que fazem da violência do capital.

\section{REFERÊNCIAS}

ADORNO, Theodor W. Televisão e os padrões da cultura de massa. In: ROSENBERG, B.; WHITE, D. M. Cultura de massa. São Paulo: Cultrix, 1973a, p. 546-562.

ADORNO, Theodor W.; HORKHEIMER, Max (Org.). Temas básicos de sociologia. São Paulo: Cultrix, Edusp, 1973b. 
ADORNO, Theodor W. Televisão, consciência e indústria cultural. In: COHN, Gabriel. Comunicação e indústria cultural. São Paulo: Editora Nacional, 1977a, p. 346-354.

ADORNO, Theodor W. A indústria cultural. In: COHN, Gabriel. Comunicação e indústria cultural. São Paulo: Editora Nacional, 1977b, p. 287-295.

ADORNO, Theodor W. Teoria estética. Lisboa: Edições 70, 2008.

ADORNO, Theodor W.; HORKHEIMER, Max. Dialética do esclarecimento. Rio de Janeiro: Zahar, 2006.

ADORNO, Theodor W. Teoria freudiana e o padrão da propaganda fascista. In: Theodor W. Adorno; ensaios sobre a psicologia social e psicanálise. São Paulo: Editora UNESP, 2015.

CHAUI, Marilena. Simulacro e poder: uma análise da mídia. São Paulo: Editora Fundação Perseu Abramo, 2006.

CHAUI, Marilena. Conferência Lula Livre: vencer a batalha da comunicação. São Paulo, Partido dos Trabalhadores. (Comunicação oral), 2018. Disponível em: <http://www. pt.org.br/veja-conferencia-lula-livre-vencer-a-batalha-da-comunicacao/>. Acesso em: 14 abr. 2018.

DUARTE, Rodrigo. Esquematismo e semiformação. Educação e Sociedade, Campinas, v. 24, n. 83, p. 441- 457, 2003a.

DUARTE, Rodrigo. O esquematismo kantiano e a crítica à indústria cultural. Studia Kantiana, Natal, v. 4, n. 1, p. 85-105, 2003b.

DUARTE, Rodrigo. Percepção como interpretação. Reflexão e Ação, Santa Cruz do Sul, v. 16, n. 2, p. 51-76, 2008.

DUARTE, Rodrigo. Indústria cultural hoje. In: DURÃO, Fabio Akcelrud; ZUIN, Antônio; VAZ, Alexandre Fernandez. Indústria cultural hoje. São Paulo: Boitempo, 2008, p. 97110.

HEINRICH, Michael. Karl Marx e o desenvolvimento da sociedade moderna; biografia e desenvolvimento de sua obra, volume 1: 1818-1841. São Paulo: Boitempo, 2018.

MARX, Karl; ENGELS, Friedrich. Sobre literatura e arte. Portugal: Editorial Estampa, 1971. 
MARX, Karl. O capital [v. 2], 2. ed. São Paulo: Nova Cultural, 1985a.

MARX, Karl. Capítulo VI inédito de O Capital; resultados do processo de produção imediata. São Paulo: Editora Moraes, 1985b.

MARX, Karl. Contribuição à crítica da economia política, 2. ed. São Paulo: Expressão Popular, 2008.

MARX, Karl. Manuscritos econômico-filosóficos. Tradução de Jesus Ranieri. São Paulo: Boitempo, 2010a.

MARX, Karl. Trabalho assalariado e capital \& salário, preço e lucro, 2. ed. São Paulo: Expressão Popular, 2010b.

RONDELLI, Elizabeth. Realidade e ficção no discurso televisivo. Letras, n. 48, p. 149207. Curitiba, 1997.

\section{FILMES}

TROPA de Elite. Direção de José Padilha. Produção de José Padilha, Marcos Prado e Eliana Soárez. Roteiro: José Padilha e Braulio Mantovani. Rio de Janeiro: Universal Pictures do Brasil, 2007.

TROPA de Elite 2; o inimigo agora é outro. Direção de José Padilha. Produção de Marcos Prado e Braulio Mantovani. Roteiro: José Padilha e Braulio Mantovani. Rio de Janeiro: Zazen Produções, 2010.

\section{DadOS DO AUTOR}

\section{André Barcellos Carlos de Souza}

Doutor em Educação pela Faculdade de Educação da Universidade Federal de Goiás (UFG). Goiás - Brasil. Professor Adjunto da Faculdade de Educação vinculado ao Núcleo de Estudos e Pesquisas em Psicologia, Educação e Cultura (NEPPEC) da Universidade Federal de Goiás (UFG), Goiânia/GO - Brasil. andrebcsouza@gmail.com

Submetido em: 22-10-2018

Aceito em: 7-5-2019 